\title{
Crystallization and Melting Behavior in Syndiotactic Polypropylene: Origin of Multiple Melting Phenomenon
}

\author{
PITT SUPAPHOL* \\ The Petroleum and Petrochemical College, Chulalongkorn University, Soi Chulalongkorn 12, Phyathai Road, Pathumwan, \\ Bangkok 10330, Thailand
}

Received 6 March 2000; accepted 10 January 2001

\begin{abstract}
The melting behavior of syndiotactic polypropylene (s-PP) after isothermal crystallization from the melt state was studied using differential scanning calorimetry (DSC) and wide-angle X-ray diffraction (WAXD) techniques. Three melting endotherms were observed for isothermal crystallization at high degrees of undercooling. The minor endotherm, located closed to the corresponding crystallization temperature, was postulated to be the melting of the secondary crystallites formed at the crystallization temperature. The low-temperature melting peak was found to be the melting of the primary crystallites formed, and the high-temperature melting peak was a result of the melting of the crystallites recrystallized during a heating scan. The triple-melting behavior observed in subsequent melting endotherms of s-PP was therefore described as contributions from melting of the secondary crystallites and their recrystallization, partial melting of the less stable fraction of the primary crystallites and their recrystallization, melting of the primary crystallites, and remelting of the recrystallized crystallites formed during the heating scan. In addition, determination of the equilibrium melting temperature for this s-PP resin according to the linear and nonlinear Hoffman-Weeks extrapolations provided values of 143.1 and $185.6^{\circ} \mathrm{C}$, respectively. (C) 2001 John Wiley \& Sons, Inc. J Appl Polym Sci 82: 1083-1097, 2001
\end{abstract}

Key words: syndiotactic polypropylene; multiple melting behavior; secondary crystallization; equilibrium melting temperature; linear and nonlinear Hoffman-Weeks extrapolations

\section{INTRODUCTION}

Syndiotactic polypropylene (s-PP) was first synthesized in the early 1960 s by Natta et al. ${ }^{1,2}$ based on Ziegler-Natta catalysis, but the resulting polymer contained a level of regioirregular defects (e.g., head to head/tail to tail type defects) that was too high, despite a fair level of syndiotactic content. A much improved s-PP was successfully synthesized in 1988 by Ewen et al. $^{3}$ based on a

\footnotetext{
* E-mail: pitt.s@chula.ac.th.

Contract grant sponsor: Chulalongkorn University.

Journal of Applied Polymer Science, Vol. 82, 1083-1097 (2001)
}

() 2001 John Wiley \& Sons, Inc. novel metallocene catalysis. The new catalyst systems made it possible to produce s-PP with much improved purity and yields, which led to renewed interest in scientific research ${ }^{4}$ and industrial applications. ${ }^{5-8}$

Recently, our group reported differential scanning calorimetry (DSC) studies on the isothermal bulk crystallization and subsequent melting behavior on various S-PP resins commercially made available by Fina Oil and Chemical Company (Dallas, TX) ${ }^{9,10}$ According to these earlier reports, subsequent DSC endothermic traces exhibited two or three distinct melting endotherms, depending on the temperature at which the samples were crystallized. Under the conditions stud- 
ied previously, ${ }^{10}$ the multiple melting behavior of s-PP was preliminarily concluded to be a result of partial melting, recrystallization of the less stabled crystallites, remelting of the recrystallized crystallites, and normal melting of the primary crystallites formed at the crystallization conditions. Although the aforementioned conclusion was satisfactory in describing our previous results, further investigations are necessary to gain a more complete understanding of subsequent melting behavior, as well as the origin of the multiple melting behavior, of s-PP after isothermal crystallization.

Multiple melting is not an exclusive phenomenon for s-PP. In fact, various investigators reported similar observations on a number of semicrystalline polymers, including some flexible polymers: polyethylene, ${ }^{11,12}$ isotactic polypropylene (i-PP), ${ }^{13,14}$ trans-1,4-polyisoprene, ${ }^{15}$ and poly(butylene succinate ${ }^{16}$; and some semistiff polymers: aliphatic polyamides, ${ }^{17-19}$ isotactic polystyrene (i-PS), ${ }^{20}$ syndiotactic polystyrene and its blends, ${ }^{21}$ poly(ethylene terephthalate), ${ }^{22-27}$ poly(butylene terephthalate), ${ }^{28-31}$ poly(phenylene sulfide), ${ }^{32,33}$ and poly(aryl ether ether ketones). ${ }^{34-50}$

A number of hypotheses were proposed to explain the occurrence of multiple melting endotherms. In the studies of isothermal crystallization under quiescent conditions (i.e., crystallization is only a function of temperature), the multiple melting behavior of these semicrystalline polymers may be designated as being the result of one of the following reasons: the presence of two (or more) crystal modifications, ${ }^{13,15}$ the presence of two (or more) crystalline morphologies, ${ }^{28}$ the presence of two populations of crystal lamellae of different thicknesses, ${ }^{35,38,40,43-45}$ and the simultaneous melting, recrystallization, and remelting of the lamellae initially formed at the crystallization conditions..$^{22,34,37,39,42,46}$

Among these models, simultaneous meltingrecrystallization-remelting and the dual-lamellar population models seem to receive much attention in explaining the multiple melting behavior in various semicrystalline polymers that do not exhibit multiple crystal modifications upon crystallizing at the crystallization conditions studied. The simultaneous melting-recrystallization-remelting model first proposed by Holdsworth and Turner-Jones ${ }^{22}$ hypothesizes that the primary lamellae formed at the crystallization temperature $\left(T_{c}\right)$ undergo a partial melting process that gives rise to an observation of the lowmelting endotherm (usually observed at ca. $10^{\circ} \mathrm{C}$ above the $T_{c}$ ). During the heating scan, the partially melted material undergoes a simultaneous process of recrystallization into thicker and more perfect lamellae that, upon melting, give rise to the observation of the high-melting endotherm. This postulated model was primarily based on the observation that the magnitude and position of the low endotherm is heating rate dependent. The suitability of the model was questioned by the experimental findings that the occurrence of the high-melting endotherm precedes that of the lowtemperature endotherm, ${ }^{36,38,47}$ which clearly contradicts the assignment of the low endotherm to the partial melting of the primary lamellae as postulated in this model.

The dual-lamellar population model, which was originally suggested by Cebe and Hong ${ }^{35}$ and Bassett et al., ${ }^{38}$ hypothesizes that a bimodal distribution of lamellae of different thicknesses exists within crystalline aggregates formed at the crystallization conditions studied, and the melting of the thin and the thick lamellae give rise to the appearance of the low- and high-temperature endotherms, respectively. The two extensions of this model ${ }^{49}$ are the dual-lamellar stack mod$\mathrm{el}^{27,31,40,47,48}$ and the lamellar insertion model. ${ }^{41,43-45}$ According to the dual-lamellar stack model, the distribution of the stacks of thick and thin lamellae is such that they exist in different stacks; in the lamellar insertion model they coexist in the same stacks with the thin lamellae distributing between two thick lamellae. The applicability of these two variants in describing the experimental data is controversial and is very dependent on the experimental conditions and perhaps on the technique used to obtain the data.

In this article, the DSC and wide-angle X-ray diffraction (WAXD) techniques were used to investigate the multiple melting behavior of s-PP after isothermal crystallization under various crystallization conditions. The objectives of this work were to obtain detailed information on the crystallization and melting mechanisms of s-PP and to propose the most likely explanation for the origin of the multiple melting behavior using the aforementioned hypotheses as guidelines.

\section{EXPERIMENTAL}

\section{Materials}

The s-PP resin (s-PP\#4) used in this study was synthesized using a metallocene catalyst and was 
produced commercially in pellet form by Fina Oil and Chemical Company (La Porte, TX). The molecular characterization data showed the following molecular weight information: the numberaverage molecular weight $\left(M_{n}\right)$ was $81,300 \mathrm{Da}$, the weight-average molecular weight $\left(M_{w}\right)$ was $171,000 \mathrm{Da}$, the $z$-average molecular weight $\left(M_{z}\right)$ was $294,000 \mathrm{Da}$, and the polydispersity $\left(M_{w} / M_{n}\right)$ was 2.1 . In addition, the syndiotacticity measured by ${ }^{13} \mathrm{C}-\mathrm{NMR}$ showed the racemic dyad content [\%r] to be $89.2 \%$, the racemic triad content [\%rr] to be $84.4 \%$, and the racemic pentad content [\% rrrr] to be $74.6 \%$. The glass-transition temperature $\left(T_{g}\right)$ was determined to be about $-6^{\circ} \mathrm{C} .{ }^{10}$

\section{Sample Preparation}

Sliced pellets were melt pressed at a pressure of about $4.6 \times 10^{2} \mathrm{MN} \mathrm{m}^{-2}$ and a temperature of $190^{\circ} \mathrm{C}$ between a pair of polyimide films, which in turn were sandwiched between a pair of thick metal plates in a Wabash compression molding machine. After a 10-min holding time, a film of about $290-\mu \mathrm{m}$ thickness was taken out and allowed to cool to room temperature at ambient conditions between the two metal plates. This treatment assumed that the previous thermomechanical history was essentially erased and provided a standard crystalline memory condition for our experiments.

\section{Apparatus and Procedures}

\section{DSC Study}

A differential scanning calorimeter (DSC-7, Perkin-Elmer) was used to record subsequent melting thermograms of s-PP samples after isothermal crystallization at various conditions. The DSC-7 was equipped with an internal cooling unit that reliably provided a cooling rate up to $200^{\circ} \mathrm{C} \mathrm{min}{ }^{-1}$. All of the recorded melting thermograms were carried out with a scanning rate of $20^{\circ} \mathrm{C} \mathrm{min}{ }^{-1}$ unless indicated otherwise. Calibration for the temperature scale was performed using a pure indium standard (equilibrium melting temperature, $T_{m}^{0}=156.6^{\circ} \mathrm{C}$; equilibrium enthalpy of fusion, $\Delta H_{f}^{0}=28.5 \mathrm{~J} \mathrm{~g}^{-1}$ ) on every other run to the ensure reliability of the data obtained. In order to minimize the thermal lag between the sample and the furnace, a single disk of the s-PP sample that was cut from the as-prepared film (ca. $6.5 \mathrm{mg}$ weight) was loaded into a DSC pan and lid. It is worth noting that each sample was used only once and all the runs were carried out under nitrogen purge to minimize thermal degradation.

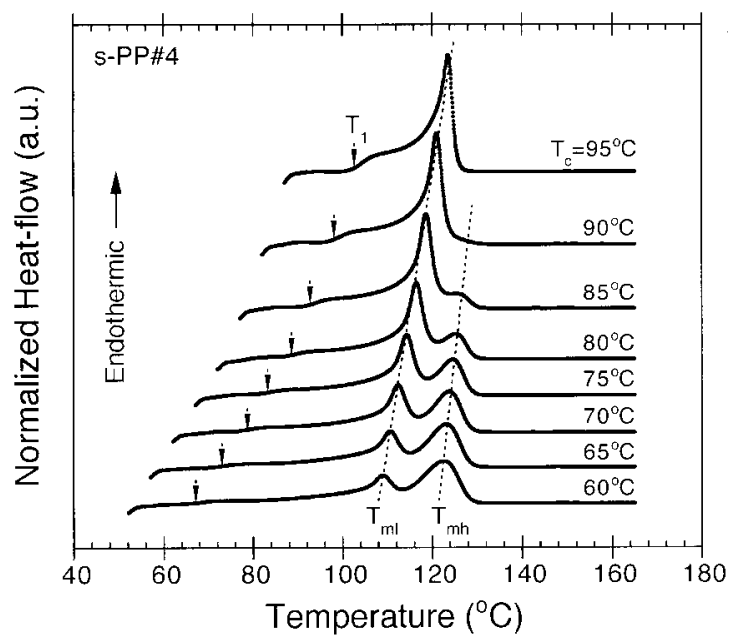

Figure 1 Melting endotherms $\left(20^{\circ} \mathrm{C} \mathrm{min}-1\right)$ of s-PP samples after isothermal crystallization from the melt state at the specified temperature. $T_{1}$, the minor peak temperature; $T_{\mathrm{ml}}$, the low-melting peak temperature; $T_{\mathrm{mh}}$, the high-melting peak temperature.

\section{WAXD Analysis}

The WAXD technique was employed to determine the crystal modification in the samples having similar thermal histories compared to those described for the DSC samples. The WAXD intensity patterns were collected on a Rigaku-Denki diffractometer $(\mathrm{Cu} \mathrm{K} \alpha$ radiation, $\lambda=1.54 \AA)$ equipped with a computerized data collection and analytical system. The operating condition of the $\mathrm{X}$-ray source was set at a voltage of $35 \mathrm{kV}$ and a current of $40 \mathrm{~mA}$.

\section{RESULTS AND DISCUSSION}

\section{Dependence of Subsequent Melting Endotherms on Crystallization Temperature}

Figure 1 presents a set of melting thermograms $\left(20^{\circ} \mathrm{C} \mathrm{min}^{-1}\right)$ for s-PP samples isothermally crystallized from the melt state at $T_{c}$ values ranging from 60 to $95^{\circ} \mathrm{C}$. Each sample was held at a fusion temperature $\left(T_{f}\right)$ of $190^{\circ} \mathrm{C}$ for $5 \mathrm{~min}$ to ensure complete melting. ${ }^{51}$ After that, the sample was quenched from $T_{f}$ at the highest achievable cooling rate allowed by the DSC to the desired $T_{c}$ where it was held until the completion of the crystallization process. The total holding time required for completion of crystallization at each $T_{c}$ varied and was found to be an increasing function of it (e.g., ca. $4 \mathrm{~min}$ at $T_{c}=60^{\circ} \mathrm{C}$ and ca. $70 \mathrm{~min}$ at 
$\left.95^{\circ} \mathrm{C}\right) .{ }^{10}$ An earlier report provides a complete discussion of the bulk crystallization kinetics for this S-PP resin. ${ }^{10}$

According to Figure 1, it is apparent that the DSC melting endotherms exhibited double-melting phenomena, particularly when the $T_{c}$ values were below $90^{\circ} \mathrm{C}$. Moreover, the low-temperature melting peak $\left(T_{\mathrm{ml}}\right)$ clearly increased in its size and sharpness, and its position shifted toward a higher temperature as the $T_{c}$ increased. On the contrary, the high-temperature melting peak $\left(T_{\mathrm{mh}}\right)$ got smaller with increasing $T_{c}$ and even disappeared when the $T_{c}$ was greater than $90^{\circ} \mathrm{C}$. Observations of the double-melting endotherms were previously reported in $\mathrm{s}-\mathrm{PP}^{52,53}$ and in syndiotactic poly(propene-co-octene) $[\mathrm{s}-\mathrm{P}(\mathrm{P}-\mathrm{co}-\mathrm{O})]{ }^{54}$ In s-PP the double-melting endotherms were observed for $T_{c}$ below about $105^{\circ} \mathrm{C}\left(M_{n}=53,200 \mathrm{Da}\right.$, $\left.M_{w} / M_{n}=1.1,[\% r]=94 \%\right)^{52}$ and below about $128^{\circ} \mathrm{C}\left(M_{n}=104,000 \mathrm{Da}, M_{w} / M_{n}=2.3\right.$, [\%rr $]=$ $97 \%) .{ }^{53}$ In s-P(P-co-O) the double-melting endotherms were observed for $T_{c}$ values below about $116.5^{\circ} \mathrm{C}\left(M_{n}=73,000 \mathrm{Da}, M_{\mathrm{w}} / M_{\mathrm{n}}=2.1\right.$, $[\% r]=$ 97\%, 4 wt \% octene counits). ${ }^{54}$ According to Figure 1 , observation of the minor endotherm $\left(T_{1}\right)$ located close to each respective $T_{c}$ is also of great interest. The presence of the minor endotherm was not a result of the enthalpic recovery of a physically aged rigid amorphous fraction present in the sample, because the $T_{g}$ for this s-PP resin was previously determined to be about $-6^{\circ} \mathrm{C},{ }^{10}$ which is apparently much lower than the temperature range where the minor endotherm was observed.

There were five terms used (see Fig. 2) to quantitatively illustrate the relationships of these melting endotherms observed in the subsequent heating scans with the $T_{c}$ : the $T_{\text {int }}$ refers to the onset temperature of the minor endotherm, the minor peak temperature $\left(T_{1}\right)$ refers to the apparent peak temperature of the minor endotherm, the low-melting peak temperature $\left(T_{\mathrm{ml}}\right)$ refers to the peak temperature of the low-temperature melting peak, the high-melting peak temperature $\left(T_{\mathrm{mh}}\right)$ refers to the peak temperature of the hightemperature melting peak, and the end temperature $\left(T_{\text {end }}\right)$ refers to the final temperature where the last crystalline aggregate melts. All of these values extracted from the DSC heating thermograms shown in Figure 1 are summarized in Table I. Plots of these values as a function of the $T_{c}$ are shown in Figure 3.

According to Table I and Figure 3, it is apparent that values of the $T_{\text {int }}$ and the $T_{1}$ steadily

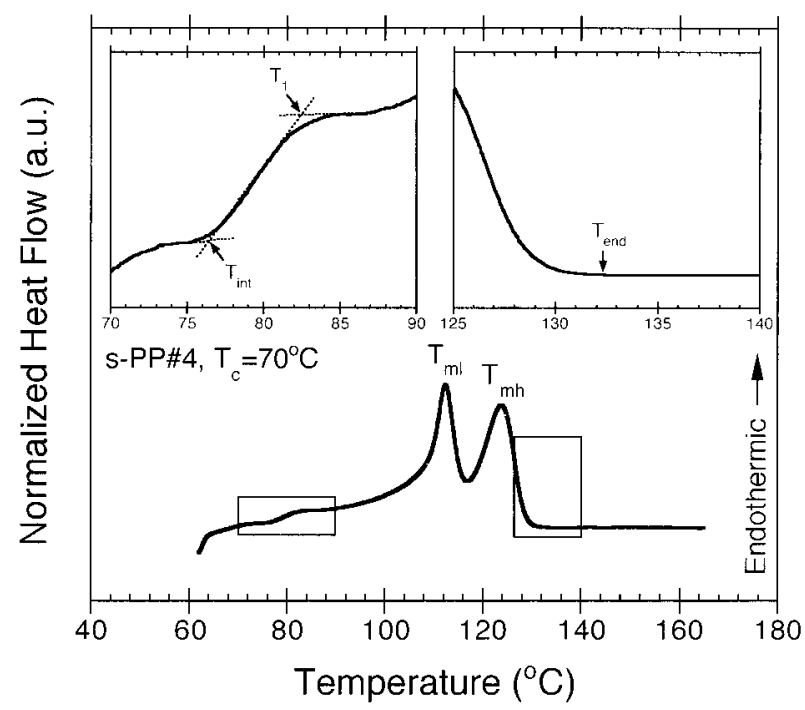

Figure 2 The procedure used to quantitatively determine characteristic temperatures from a subsequent melting endotherm. $T_{\text {int }}$, the initial temperature; $T_{1}$, the minor peak temperature; $T_{\mathrm{ml}}$, the low-melting peak temperature; $T_{\mathrm{mh}}$, the high-melting peak temperature; $T_{\text {end }}$, the end temperature.

increased with increasing $T_{c}$. Interestingly, the difference between each value of the $T_{\text {int }}$ and the $T_{1}$ and $T_{c}$ were found to be nearly constant within the $T_{c}$ range studied (i.e., $T_{\text {int }}-T_{c}=6.5 \pm 0.3^{\circ} \mathrm{C}$ and $\left.T_{1}-T_{c}=11.8 \pm 0.4^{\circ} \mathrm{C}\right)$. This finding suggested that melting always started at a temperature close to the respective $T_{c}$ (ca. $T_{c}+6.5^{\circ} \mathrm{C}$ ). It was also evident that the values of the $T_{\mathrm{ml}}$ and the $T_{\mathrm{mh}}$ steadily increased with increasing $T_{c}$. However, the values of the $T_{\mathrm{mh}}$ were less dependent on $T_{c}$ than were those of the $T_{\mathrm{ml}}$. Unlike the others, the $T_{\text {end }}$ value (ca. $132.1 \pm 0.8^{\circ} \mathrm{C}$ on average) did not appear to be affected by changes in the $T_{c}$. In addition, value of the total enthalpy of fusion $\left(\Delta H_{f}\right)$ slightly increased with increasing $T_{c}$, suggesting that the apparent degree of crystallinity $\left(\chi_{c}^{D S C}\right)$ is a weak increasing function with the $T_{c}$ (within the $T_{c}$ range studied).

Analysis and discussion of the multiple melting behavior cannot be complete without a proper consideration of whether the samples possessed more than one crystal modification within the $T_{c}$ range studied. Figure 4 illustrates WAXD diffractograms for samples isothermally crystallized in a Mettler hot stage at $T_{c}$ 's of $60,70,80,85,90$, and $95^{\circ} \mathrm{C}$, respectively. After each sample was melted in a Mettler hot stage at a $T_{f}$ of $190^{\circ} \mathrm{C}$ for $5 \mathrm{~min}$, it was quickly transferred to another Mettler hot stage, the temperature of which had been set at 
Table I Variation of Initial Temperature $\left(T_{\text {int }}\right)$, Minor Peak Temperature $\left(T_{1}\right)$, Low-Melting Peak Temperature $\left(T_{\mathrm{ml}}\right)$, High-Melting Peak Temperature $\left(T_{\mathrm{mh}}\right)$, End Temperature $\left(T_{\text {end }}\right)$, and Enthalpy of Fusion $\left(\Delta H_{f}\right)$ Determined from Figure 1 with Crystallization Temperature $\left(T_{c}\right)$

\begin{tabular}{|c|c|c|c|c|c|c|}
\hline $\begin{array}{c}T_{c} \\
\left({ }^{\circ} \mathrm{C}\right)\end{array}$ & $\begin{array}{l}T_{\text {int }} \\
\left({ }^{\circ} \mathrm{C}\right)\end{array}$ & $\begin{array}{c}T_{1} \\
\left({ }^{\circ} \mathrm{C}\right)\end{array}$ & $\begin{array}{l}T_{\mathrm{ml}} \\
\left({ }^{\circ} \mathrm{C}\right)\end{array}$ & $\begin{array}{l}T_{\mathrm{mh}} \\
\left({ }^{\circ} \mathrm{C}\right)\end{array}$ & $\begin{array}{l}T_{\text {end }} \\
\left({ }^{\circ} \mathrm{C}\right)\end{array}$ & $\begin{array}{c}\Delta H_{f} \\
\left(\mathrm{~J} \mathrm{~g}^{-\mathbf{1}}\right)\end{array}$ \\
\hline 60 & 66.1 & 72.5 & 108.9 & 122.5 & 132.1 & 33.1 \\
\hline 65 & 71.0 & 76.3 & 110.6 & 123.0 & 132.8 & 33.2 \\
\hline 70 & 76.7 & 82.3 & 112.3 & 123.8 & 132.4 & 33.0 \\
\hline 75 & 81.5 & 86.8 & 114.2 & 124.6 & 132.6 & 33.3 \\
\hline 80 & 86.9 & 91.9 & 116.4 & 125.3 & 132.6 & 33.4 \\
\hline 85 & 91.4 & 96.5 & 118.6 & - & 132.3 & 33.4 \\
\hline 90 & 96.4 & 101.6 & 121.0 & - & 131.6 & 34.0 \\
\hline 95 & 101.6 & 106.7 & 123.6 & - & 130.2 & 34.5 \\
\hline
\end{tabular}

the desired $T_{c}$. As soon as the total time required for the completion of the crystallization process at the $T_{c}$ (equivalent to the total time interval observed in DSC) was reached, the sample was quenched in liquid nitrogen to prevent a further change in crystallinity due to the residual thermal energy within the sample.

Before going further in the analysis of the WAXD diffractograms, it is rudamentary to acquire information on all of the possible crystal modifications of s-PP available in the literature. To date, four limit-ordered crystalline modifications of s-PP were proposed and described in the literature. ${ }^{55-69}$ Of the four crystalline forms, only

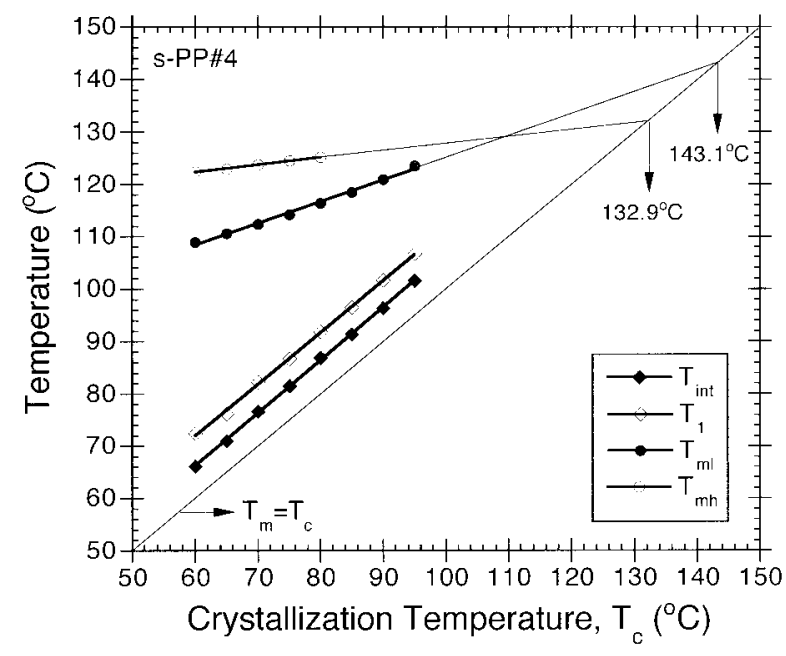

Figure 3 The variation of the initial temperature $\left(T_{\text {int }}\right)$, the minor peak temperature $\left(T_{1}\right)$, the low-melting peak temperature $\left(T_{\mathrm{ml}}\right)$, and the high-melting peak temperature $\left(T_{\mathrm{mh}}\right)$ with the crystallization temperature as determined from the subsequent melting endotherms shown in Figure 1. the molecular chain packing models of the limitordered form $\mathrm{I}^{56-59,64,66}$ and the limit-disordered form $\mathrm{I}^{59,63,66}$ (after the most recent nomenclature given by De Rosa et al. $^{70}$ ) are appropriate for characterizing s-PP samples that are crystallized under quiescent conditions from the melt state (or from solution).

Limit-ordered form I is characterized by chains in the (TTGG) ${ }_{2}$ helical conformation $[\mathrm{s}(2 / 1) 2 \mathrm{sym}$ metry] that are fully antichirally packed in an orthorhombic unit cell with $a, b$, and $c$ axes of $14.5,11.2$, and $7.4 \AA$, respectively (see Fig. $1 \mathrm{~A}$ in De Rosa et al. $\left.{ }^{70}\right)$. The axes of the helices are in the positions $(0,0, z)$ and $(1 / 2,0, z)$ of the unit cell. The characteristic X-ray peaks in the powder spectrum are observed at angles $(2 \theta)$ of $12.2^{\circ}, 15.8^{\circ}$,

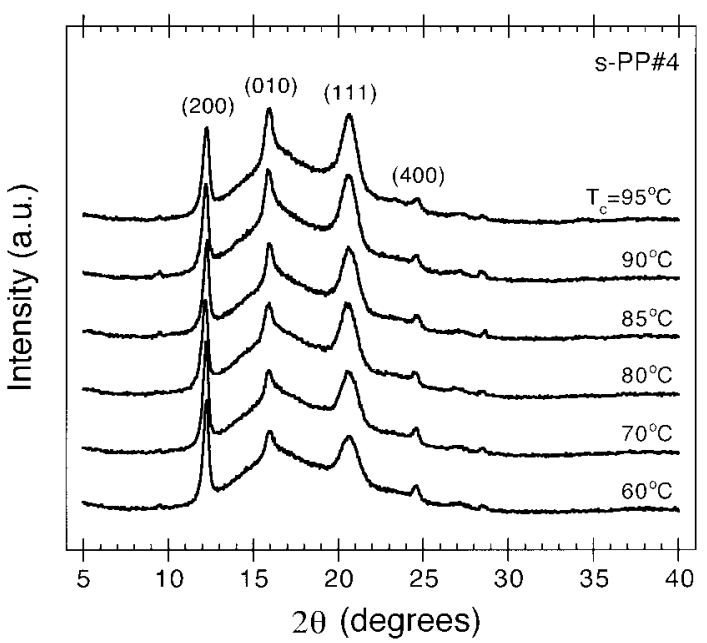

Figure 4 Wide-angle X-ray diffractograms of s-PP samples isothermally crystallized from the melt at the specified temperature corresponding to the conditions used for the thermal analysis shown in Figure 1. 
$18.9^{\circ}, 20.8^{\circ}$, and $24.5^{\circ}(d=7.25,5.60,4.71,4.27$, and $3.63 \AA$, respectively), corresponding to the observations of (200), (020), (211), (121), and (400) reflection planes, respectively. The space group proposed for this crystal form was $I b c a^{56,59}$ (or $P 2_{1} / a$ in the refined model proposed by De Rosa et al. ${ }^{64}$ ). The existence of form I is mainly controlled by the amounts of defects present in the packing of the chains, ${ }^{59,63,66}$ which is revealed by either the weakness or the absence of the (211) reflection at $2 \theta=18.9^{\circ}$ in samples crystallized at low $T_{c}$ values. The greater the amount of defects present, the higher the deviation from the fully antichiral packing is. ${ }^{66}$ For samples crystallized at low $T_{c}$ values, the limit-disordered form I was described that had an orthorhombic unit cell with $a, b$, and $c$ axes of 14.5, 5.6, and 7.4 $\AA$, respectively (see Fig. 1B in De Rosa et al. ${ }^{70}$ ), and antichiral packing of chains only along the $a$ axis. The space group proposed for this crystal form was $P c a a^{56,62}$ (or $P c a 2_{1}$ in the less symmetric arrangement of chains in the lattice ${ }^{56}$ ). According to this unit cell, the characteristic X-ray peaks are observed at $2 \theta$ $=12.2^{\circ}, 15.8^{\circ}, 20.8^{\circ}$, and $24.5^{\circ}(d=7.25,5.60$, 4.27 , and $3.63 \AA$, respectively), corresponding to the observations of (200), (010), (111), and (400) reflection planes, respectively.

According to the WAXD diffractograms shown in Figure 4, the characteristic crystalline peaks at the scattering angles $2 \theta=12.18^{\circ} \pm 0.03^{\circ}, 15.93^{\circ}$ $\pm 0.03^{\circ}, 20.60^{\circ} \pm 0.08^{\circ}$, and $24.57^{\circ} \pm 0.05^{\circ}$ were evident and the characteristic (211) reflection at $2 \theta=18.9^{\circ}$ of the limit-ordered form I was absent from all of the WAXD scans. The results indicated that, within the $T_{c}$ range studied, s-PP crystallized in the limit-disordered form I. As a result, the hypothesis of multiple crystal modifications as the source of the multiple melting behavior of $\mathrm{s}-\mathrm{PP}$ could be ruled out. Because of this and the facts that the $T_{\mathrm{ml}}$ became more resolved and shifted toward a higher temperature as the $T_{c}$ increased and the $T_{\mathrm{mh}}$ exhibited otherwise, it was established that formation of the $T_{\mathrm{ml}}$ was a result of the melting process of the primary crystallites formed at the respective $T_{c}$. The discussion on the occurrence of the minor endotherm and the $T_{\mathrm{mh}}$ is given in subsequent sections.

\section{Dependence of Subsequent Melting Endotherms on Crystallization Time Interval}

As mentioned previously, the simultaneous melting-recrystallization-remelting and dual-lamellar population models received much attention

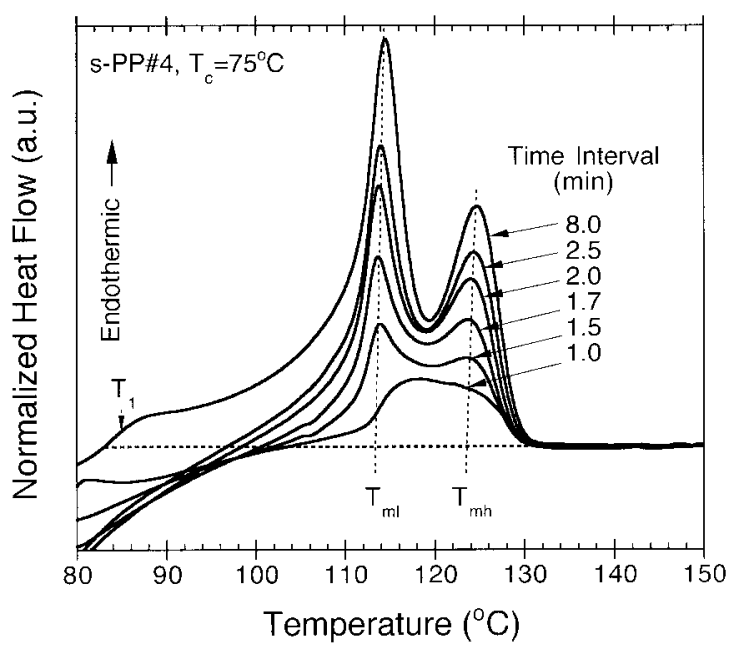

Figure 5 Melting endotherms $\left(20^{\circ} \mathrm{C} \min ^{-1}\right)$ of $\mathrm{s}-\mathrm{PP}$ samples after partial and complete crystallization at $\left(T_{c}\right) 75^{\circ} \mathrm{C}$ for different crystallization time intervals as indicated.

and were applied to describe the multiple melting phenomena in various semicrystalline polymers. It was stated in the previous section that the $T_{\mathrm{ml}}$, not the $T_{1}$, was attributed to the melting of the primary crystallites formed at the $T_{c}$. As a result, the simultaneous melting-recrystallization-remelting model was ruled out to describe the multiple melting behavior of s-PP. This left only one possible explanation, the dual-lamellar population model, which proposed that the occurrence of the minor endotherm was a result of the melting of the secondary crystals formed at the $T_{c}$. It is a known fact that secondary crystallization is a very slow process and often lags behind primary crystallization. If the minor endotherm observed in subsequent melting scans of s-PP was indeed attributed to the melting of the secondary crystals, one would expect that it should not be present in subsequent melting endotherms recorded at early stages of crystallization (i.e., partial crystallization for short time intervals at the $T_{c}$ ).

Figure 5 illustrates some representative DSC melting thermograms of s-PP (recorded at $20^{\circ} \mathrm{C}$ $\mathrm{min}^{-1}$ ) after isothermal crystallization at a $T_{c}$ of $75^{\circ} \mathrm{C}$ for $1.0,1.5,1.7,2.0,2.5$, and $8.0 \mathrm{~min}$. Figure 6 shows DSC melting thermograms (recorded at $20^{\circ} \mathrm{C} \mathrm{min}^{-1}$ ) after isothermal crystallization at a $T_{c}$ of $95^{\circ} \mathrm{C}$ for $15,20,25,30,40$, and $50 \mathrm{~min}$. At a $T_{c}$ of $75^{\circ} \mathrm{C}$, a time interval of at least $0.5 \mathrm{~min}$ was required for a melting peak to be observed in the subsequent melting endotherm (not shown) 


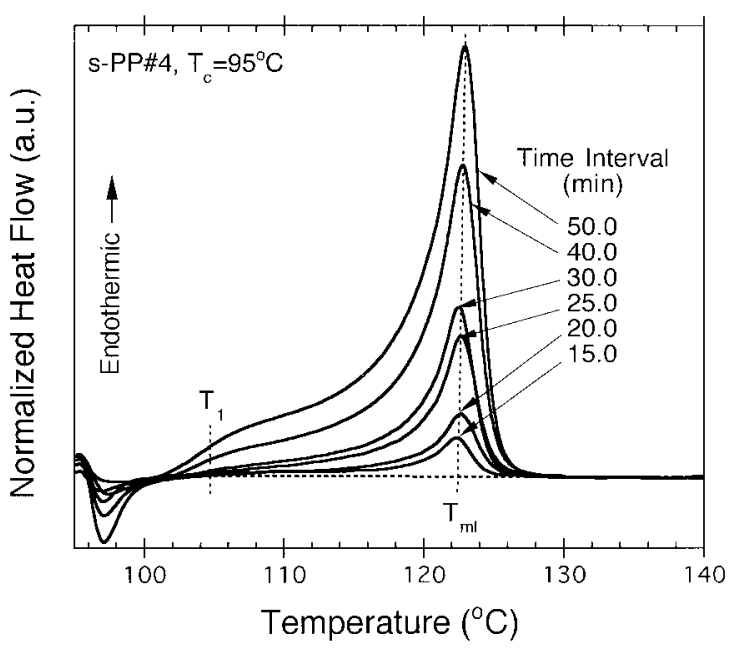

Figure 6 Melting endotherms $\left(20^{\circ} \mathrm{C} \min ^{-1}\right)$ of s-PP samples after partial and complete crystallization at $\left(T_{c}\right) 95^{\circ} \mathrm{C}$ for different crystallization time intervals as indicated.

whereas it was at least $5 \mathrm{~min}$ in the case of crystallization at a $T_{c}$ of $95^{\circ} \mathrm{C}$. For the first approximation, the time intervals of about 0.5 and $5 \mathrm{~min}$ corresponded to the induction time needed for stable crystallites to be formed at $T_{c}$ values of 75 and $95^{\circ} \mathrm{C}$, respectively.

A thorough examination of these melting thermograms suggested that the occurrence of the secondary crystallization may be decisively determinable. At a $T_{c}$ of $75^{\circ} \mathrm{C}$, the minor endotherm located at the low-temperature region was clearly discernable after partial crystallization for $8 \mathrm{~min}$. At a $T_{c}$ of $95^{\circ} \mathrm{C}$, the minor endotherm was apparent after partial crystallization for 40 and $50 \mathrm{~min}$. Careful examination of all of the recorded DSC thermograms (some of which are not shown in the figures) confirmed that the appearance of the minor endotherms was not clearly observed until after partial crystallization for at least about 4 min at a $T_{c}$ of $75^{\circ} \mathrm{C}$ and for at least about $25 \mathrm{~min}$ at a $T_{c}$ of $95^{\circ} \mathrm{C}$. The position where the minor endotherm was observed was located close to a temperature where the sample was crystallized, as previously mentioned, and seemed to shift to a higher temperature with an increasing crystallization time interval at the respective $T_{c}$ values.

The facts that the minor endotherm was usually observed at a temperature close to $T_{c}$, it was observed at a later stage of the crystallization process, and it increased in magnitude and possibly shifted toward a higher temperature with increasing crystallization time suggested that its existence corresponded to a contribution from a rather slow crystallization mechanism occurring at the $T_{c}$, which was most likely a result of the secondary crystallization. At this point, it is logical to establish that the minor endotherm and the $T_{\mathrm{ml}}$ were caused by the melting of the secondary and primary crystallites, respectively, that were formed at the $T_{c}$.

In addition to their use for determining the source of the minor endotherm, Figures 5 and 6 provide us with additional information on the melting behavior of s-PP. According to Figures 5 and 6 , the positions of the $T_{\mathrm{ml}}$, which were taken as the melting endotherm of the primary crystallites formed at the $T_{c}$, were essentially unchanged with increasing crystallization time intervals. The average values of these peaks were 114.1 $\pm 0.2^{\circ} \mathrm{C}$ for a $T_{c}$ of $75^{\circ} \mathrm{C}$ and $123.2 \pm 0.1^{\circ} \mathrm{C}$ for a $T_{c}$ of $95^{\circ} \mathrm{C}$. According to the Gibbs-Thomson (GT) equation, ${ }^{71,72}$ a relationship exists between the observed melting temperature $\left(T_{m}\right)$ and the lamellar thickness $\left(l_{c}\right)$ of the crystallites:

$$
T_{m}=T_{m}^{0}\left(1-\frac{2 \sigma_{e}}{\Delta H_{f}^{0}} \cdot \frac{1}{l_{c}}\right)
$$

where $T_{m}^{0}$ is the melting point of an infinitely thick crystal for the studied polymer and $\sigma_{e}$ is the fold surface free energy. According to eq. (1), the positions of the $T_{\mathrm{ml}}$ are essentially constant, which suggests that the average thickness of the primary crystallites formed at each $T_{c}$ is essentially constant throughout the crystallization process. In other words, the results suggest that the primary crystallites formed at the $T_{c}$ do not thicken during the course of crystallization. This finding is in excellent agreement with the observations reported on the crystallization behavior of s-PP using a real-time small-angle X-ray scattering and DSC technique, ${ }^{53,54,73}$ in which the average lamellar thickness of the primary crystallites of s-PP was shown to be constant during both the isothermal crystallization process and subsequent heating to the melting point.

Before discussing the origin of the $T_{\mathrm{mh}}$, it is interesting to establish hypotheses regarding the melting mechanisms of the secondary crystallites formed at the $T_{c}$ during subsequent heating. In order to do so, the nature of the secondary crystallites must first be established. This discussion is based on the two variance ${ }^{27,31,40,41,43-45,47,48}$ of the dual-lamellar population model ${ }^{35,38}$ and a recent notion on secondary crystallization in polymers proposed by Marand and Alizadeh. ${ }^{74}$ 
It is well established that overall crystallization in semicrystalline polymers can be divided into two main processes: primary crystallization and secondary crystallization. Primary crystallization corresponds to the macroscopic development of crystallinity as a result of two consecutive microscopic mechanisms: primary nucleation and secondary nucleation (i.e., subsequent crystal growth). The formation of chain-folded lamellae (i.e., primary nucleation) leads to further growth of the lamellae through the processes of branching and splaying (e.g., see Fig. 4 in Vancso et al. ${ }^{75}$ ). The degree of branching and splaying is mainly controlled by the degree of undercooling (i.e., the difference between the $T_{m}^{0}$ and the $T_{c}: \Delta T$ $=T_{m}^{0}-T_{c}$ ) in an increasing manner. The evidence to this assertion can be seen in a series of atomic force microscopy images of the crystal growth in i-PS taken by Taguchi et al. ${ }^{76}$ in which they showed that the degree of branching and splaying in crystalline aggregates increases with an increasing degree of undercooling. The primary crystallization is assumed to cease when no further growth of the lamellae can take place. This may be due to the impingement of the crystalline aggregates onto one another.

Secondary crystallization refers to any process leading to a further increase in the absolute crystallinity. Two important processes are envisioned: the thickening of the primary lamellae and the formation of secondary lamellae from crystallizable amorphous materials trapped between two different lamellae in the same stack (i.e., interlamellar amorphous layer) or between two different stacks of lamellae (i.e., interfibrillar amorphous materials). The thickening mechanism is thermodynamically driven by the reduction of the specific surfaces of the crystals (hence, less free enthalpy is penalized for the formation of free surfaces), but it is hampered by the kinetics factors (e.g., molecular mobility). In the case of copolymers with noncrystallizable counits, the lamellar thickening is also less favorable due to the clamping effect caused by high concentration of the noncrystallizable counits rejected from the growing lamellae around the basal planes and the growth fronts. This clamping effect was thought to be the main reason for the observed constancy in the lamellar thickness during the course of crystallization in s-PP. ${ }^{54}$

Even though it is obvious that secondary lamellae must somehow originate from either interlamellar or interfibrillar crystallizable amorphous materials (or both) trapped within the crys- talline aggregates after their impingement to one another, the mechanisms by which the formation of the secondary lamellae are followed are uncertain and are still matters of ongoing research. However, we believe that the explanation may lie in our understanding of the nature of the interlamellar amorphous layers and the interfibrillar amorphous materials at certain crystallization conditions.

For crystallization at high undercoolings, the facts that the degree of branching and splaying is relatively high and the interlamellar amorphous layers are relatively thick suggests that secondary lamellae may originate from the interlamellar amorphous layers, rather than from the free melt between the fibrillar structures (i.e., less interfibrillar melt is available due to a high order of branching and splaying). Because the interlamellar amorphous layers comprises mainly folds, tie molecular segments, chain ends, and other rejected noncrystallizable materials, secondary lamellae can only form from tie molecular segments that are constrained at both ends between two different lamellae. In the conditions of conformational constraints, the reduction in the molecular entropy causes the apparent $T_{m}^{0}$ of the particular molecular segments to be higher than normal. Relatively thinner secondary lamellae can therefore become stable at these temperatures. As postulated by Marand and Alizadeh, ${ }^{74}$ the secondary crystallites, in this extreme case, are believed to only originate from a mechanism similar to a fringed micelle or chain clustering (see Fig. 1 in Marand and Alizadeh ${ }^{74}$ ) because of extreme conformational constraints at both ends. On the other hand, for crystallization at low undercoolings, the reverse of the reasons given above suggests to us that it is possible for new lamellae to grow from the relatively free melt located between the fibrillar structures, resulting in relatively slight differences between the primary and secondary lamellae formed. ${ }^{74}$ For crystallization under intermediate conditions, intermediate situations for the formation of the secondary crystallites after the impingment of the primary crystallites are expected. The characteristics of the secondary crystallites (e.g., thickness, stability, etc.) greatly depends on the degree of undercooling and the magnitude of the conformational constraints. $^{74}$

Because under the same crystallization conditions the thickness of the secondary crystallites are thinner than that of the primary crystallites (thus less stability), upon heating these second- 
ary crystallites melt first. Whether the secondary crystallites are formed in the lamellar insertion or the lamellar stack mode may depend largely on the conditions of crystallization and the types of polymers with which one is dealing. Similar to the crystallization mechanisms, melting mechanisms for both primary and secondary crystals are also complicated. Upon melting, a finite relaxation time is required before a bundle of molecular segments, after the detachment from the crystals, resumes its equilibrium molten state (i.e., random coil conformation); this characteristic time varies from one polymer to another. In s-PP it was recently shown that the relaxation time for the segregation of a nucleation cluster to its equilibrium molten state (i.e., complete melting) strongly depends on the temperature at which the sample is brought to melt (i.e., $T_{f}$ ) in a decreasing manner with increasing temperature. ${ }^{51}$ Because the secondary crystallites are shown to melt close to the $T_{c}$ where they are formed due to the thinness and the relatively low stability of the lamellae formed, the relaxation time required for the detached or melted bundles of molecular segments to resume their equilibrium molten state is tremendously large, causing the detached bundles of molecular segments to retain their orderedness (i.e., the conformational state they assume in the crystalline phase). Upon further heating these bundle of molecular segments can act as predetermined nuclei that recrystallize during the heating scan.

\section{Dependence of Subsequent Melting Endotherms on Heating Rate}

Without exceptions, the recrystallization process during the heating scan must obey the fundamentals of polymer crystallization, even though the mechanisms behind the process may be completely different. Although the requirement for the formation of recrystallized nuclei was stated in the previous section, the following questions still remain:

1. What exactly is the mechanism for the diffusion of molecular segments onto the growth fronts during the recrystallization process?

2. What is the nature of the lamellae formed (chain folded, true fringed micellar, or a mixture of both)?

3. Because the recrystallized lamellae has to grow during a dynamic temperature

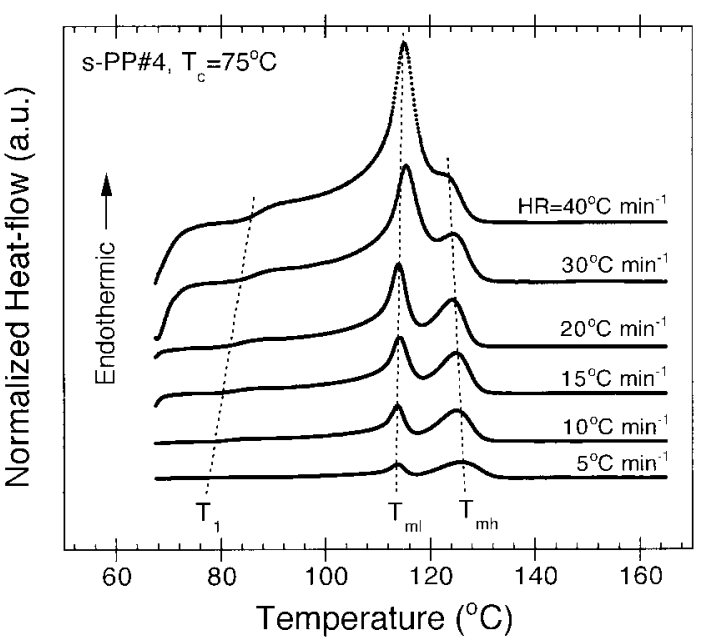

Figure 7 Melting endotherms of s-PP samples recorded using different heating rates ranging from 5 to $40^{\circ} \mathrm{C} \min ^{-1}$ after complete crystallization at $\left(T_{c}\right) 75^{\circ} \mathrm{C}$.

change, is the thickness of the formed lamellae constant or increasing as the temperature increases?

Whether these questions can be answered is immaterial at this point. One can expect that the extent of the recrystallization process from the crystallizable materials due to the melting of the secondary crystallites significantly depends on the original $T_{c}$ where the secondary crystallites were formed, the chemical structure of the polymers studied, and the scanning rate used during the heating scan in the DSC. In addition, one can expect that the melting point of these recrystallized crystals must be higher than that of the primary crystals formed at $T_{c}$. The last postulation gives us confidence that the $T_{\mathrm{mh}}$ values observed in Figures 1 and 5 are a result of the melting of the recrystallized crystallites formed during the heating scan.

To account for the effect of the heating rate on the multiple melting behavior of s-PP, a separate qualitative experiment was conducted. The results are shown in Figure 7. In this experiment each sample was isothermally crystallized at $75^{\circ} \mathrm{C}$, and then its melting thermogram was recorded using six different scanning rates ranging from 5 to $40^{\circ} \mathrm{C} \mathrm{min}^{-1}$. It should be noted that before each measurement was carried out at a designated scanning rate, the DSC had been well calibrated for its temperature scale for that particular scanning rate. According to Figure 7, the weight fraction of the $T_{\mathrm{mh}}$ was found to decrease 
Table II Variation of Initial Temperature $\left(T_{\text {int }}\right)$, Minor Peak Temperature $\left(T_{1}\right)$, Low-Melting Peak Temperature $\left(T_{\mathrm{ml}}\right)$, High-Melting Peak Temperature $\left(T_{\mathrm{mh}}\right)$, End Temperature $\left(T_{\text {end }}\right)$, and Enthalpy of Fusion $\left(\Delta H_{f}\right)$

\begin{tabular}{|c|c|c|c|c|c|c|}
\hline $\begin{array}{l}\text { Heat Rate } \\
\left({ }^{\circ} \mathrm{C} \min ^{-1}\right)\end{array}$ & $\begin{array}{l}T_{\text {int }} \\
\left({ }^{\circ} \mathrm{C}\right)\end{array}$ & $\begin{array}{l}T_{1} \\
\left({ }^{\circ} \mathrm{C}\right)\end{array}$ & $T_{\mathrm{ml}}\left({ }^{\circ} \mathrm{C}\right)$ & $T_{\mathrm{mh}}\left({ }^{\circ} \mathrm{C}\right)$ & $T_{\text {end }}\left({ }^{\circ} \mathrm{C}\right)$ & $\begin{array}{c}\Delta H_{f} \\
\left(\mathrm{~J} \mathrm{~g}^{-1}\right)\end{array}$ \\
\hline 5 & 78.2 & 81.9 & 113.3 & 125.6 & 133.9 & 35.8 \\
\hline 10 & 79.4 & 84.0 & 113.6 & 124.9 & 133.6 & 34.1 \\
\hline 15 & 79.5 & 85.9 & 114.4 & 124.9 & 133.5 & 34.1 \\
\hline 20 & 80.3 & 86.2 & 114.0 & 124.2 & 132.7 & 33.9 \\
\hline 30 & 83.0 & 89.3 & 115.4 & 124.2 & 132.7 & 33.1 \\
\hline \multirow[t]{2}{*}{40} & 84.0 & 90.2 & 115.1 & 123.2 & 132.0 & 32.6 \\
\hline & & & $114.3 \pm 0.8$ & $124.5 \pm 0.8$ & $133.1 \pm 0.7$ & $34.0 \pm 1.1$ \\
\hline
\end{tabular}

The variations were determined from Figure 7 with the heating rate used to record the subsequent melting endotherms after complete crystallization at $\left(T_{c}\right) 75^{\circ} \mathrm{C}$.

with increasing heating rate while that of the lower melting peak increased. This can be explained by the fact that the rate of recrystallization is significantly dependent on the heating rate used during the heating scan. The higher the heating rate used, the shorter is the time available for the diffusion of the molecular segments onto the growing recrystallizing lamellae. In other words, the extent of the recrystallization is kinetically controlled and decreases with an increase in the heating rate used. This finding is in accordance with the results of Carfagna et al. ${ }^{77}$ in their work on the recrystallization kinetics of i-PP.

Based on the procedure given in Figure 2, the quantitative description of the melting endotherms shown in Figure 7 is summarized in Table II. Apparently, the $T_{\text {int }}$ and the $T_{1}$ were steadily increased with the increase in the scanning rate used during the heating scan. In addition, the $T_{\mathrm{ml}}$ slightly increased while the $T_{\mathrm{mh}}$ and the $T_{\text {end }}$ both decreased with increasing heating rate. The reason for the increase in the observed $T_{\text {int }}, T_{1}$, and $T_{\mathrm{ml}}$ values may be as simple as a superheating effect while that for the decrease in the observed $T_{\mathrm{mh}}$ must be based on a more theoretical grounds. It was mentioned previously that, as the scanning rate during a heating scan increases, less time is available for molecular transport onto the growth front of the recrystallizing crystallites. As a result, the recrystallized crystallites formed at a high scanning rate are less stable than those formed at a lower scanning rate, hence the lower value of the observed $T_{\mathrm{mh}}$. In addition, the $\Delta H_{f}$, which is also listed in Table II, was slightly decreased with the increasing heating rate used, suggesting that either the extent of recrystalliza- tion decreased with the increasing heating rate or the $T_{\mathrm{mh}}$ was not only attributed to the remelting of the recrystallized crystals formed from the crystallizable materials due to the melting of the secondary crystals during the heating scan but also to the remelting of the recrystallized crystals formed from the crystallizable materials due to the melting of the less stable fraction of the primary crystallites formed at the $T_{c}$.

Referring now to Figure 5, it was already established that secondary crystallization did not occur during isothermal crystallization at a $T_{c}$ of $75^{\circ} \mathrm{C}$ until a crystallization time of at least $4 \mathrm{~min}$ was reached. Yet, most of the subsequent melting endotherms after partial crystallization for various crystallization time intervals of less than 4 min (i.e., early stages of crystallization where only primary crystallization supposedly dominates) also exhibited dual-melting behavior. This suggested that melting of the less stable fraction of the primary crystallites may have occurred and upon remelting after recrystallization it gave rise to the formation of the $T_{\mathrm{mh}}$. In order to investigate the impact of the scanning rate during a heating scan on the melting of the less stable fraction of the primary crystallites and their recrystallization behavior, subsequent melting endotherms after isothermal crystallization for various short time intervals during the early stages of crystallization were recorded as a function of the heating rate (Figs. 8 and 9). A quantitative description of the results shown in Figures 8 and 9 is summarized in Table III.

In Figures 8 and 9 the subsequent melting endotherms after isothermal crystallization at a $T_{c}$ of $75^{\circ} \mathrm{C}$ for $1.5 \mathrm{~min}$ and at a $T_{c}$ of $95^{\circ} \mathrm{C}$ for 15 min are displayed for five different heating rates 


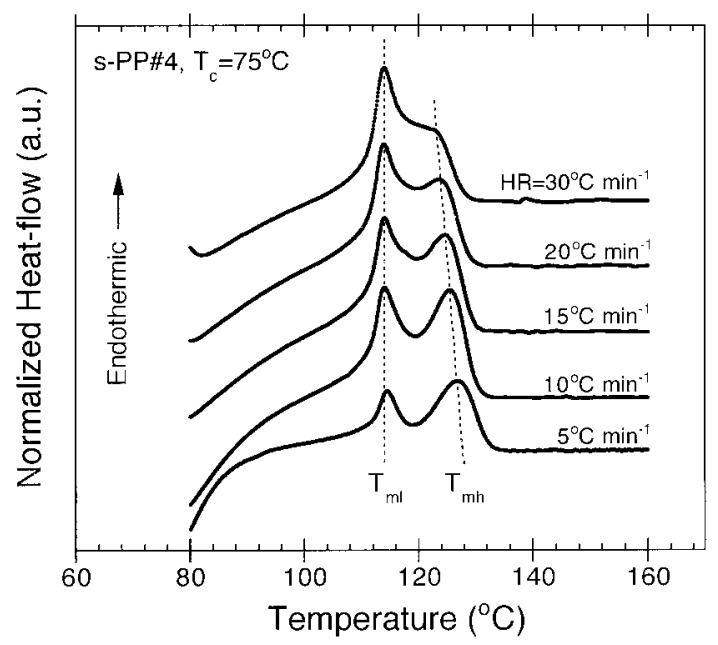

Figure 8 Melting endotherms of s-PP samples recorded using different heating rates ranging from 5 to $30^{\circ} \mathrm{C} \min ^{-1}$ after partial crystallization at $\left(T_{c}\right) 75^{\circ} \mathrm{C}$ for $1.5 \mathrm{~min}$.

ranging from 5 to $30^{\circ} \mathrm{C} \mathrm{min}^{-1}$. It was apparent that the minor endotherm did not exist in any of the thermograms recorded, suggesting that appreciable secondary crystallization had not yet occurred during the indicated time interval that the samples were held at the $T_{c}$. The weight and the peak positions $T_{\mathrm{ml}}$ of the low-temperature melting peak (see Table III for quantitative results) slightly increased with the increasing heating rate used, while those of the $T_{\mathrm{mh}}$ decreased. In Figure 9 it is evident that the $T_{\mathrm{mh}}$ was present in subsequent melting endotherms recorded at low heating rates (i.e., $\leq 10^{\circ} \mathrm{C} \mathrm{min}^{-1}$ ). This clearly verified our hypothesis that during the heating scans the less stable fraction of the primary crystallites melts and recrystallizes and upon further heating the recrystallized crystallites melts again, giving rise to the formation of the $T_{\mathrm{mh}}$. The extent of the melting and recrystallization of the primary crystallites strongly depended on the stability of the primary crystallites and the heating rate used.

\section{Equilibrium Melting Temperature}

It was proven previously that the peak value of the $T_{\mathrm{ml}}$ corresponded to the melting of the primary crystals formed at a specified $T_{c}$; thus, the $T_{\mathrm{ml}}$ values listed in Table I are simply the $T_{m}$ values of the crystalline aggregates formed in the samples after crystallization at the $T_{c}$. According to a theory derived by Hoffman and Weeks, ${ }^{78}$ the
$T_{m}^{0}$ (i.e., the melting temperature of infinitely extended crystals) can be obtained by linear extrapolation of the observed $T_{m}-T_{c}$ data to the line $T_{m}$ $=T_{c}$. Mathematically, they arrived at the following equation, the linear Hoffman-Weeks extrapolation (LHW):

$$
T_{m}=\frac{T_{c}}{2 \beta}+T_{m}^{0}\left[1-\frac{1}{2 \beta}\right]
$$

where $\beta$ is the thickening ratio. In other words, $\beta$ indicates the ratio of the thickness of the mature crystal $l_{c}$ to that of the initial one $l_{c}{ }^{*}$; therefore, $\beta$ $=l_{c} / l_{c}{ }^{*}$, which is supposed to always be greater than or equal to one. It should be noted that factor 2 in eq. (2) suggests that the thickness of the crystals undergoing melting is approximately double that of the initial critical thickness. ${ }^{79}$

Figure 3 shows the plot of $T_{\mathrm{ml}}$ (or the observed $T_{m}$ value of the crystallites formed at $T_{c}$ ) as a function of the $T_{c}$. It was evident that the $T_{\mathrm{ml}}$ values exhibited a linear relationship with the $T_{c}$, at least within the $T_{c}$ range of interest. The intersection of a least-squares line fit drawn to the bulk of the data with the line $T_{m}=T_{c}$ provided the values of $T_{m}^{0}$ (i.e., $T_{m}^{0}=143.1^{\circ} \mathrm{C}$ ). From the slope of the least-squares line fit, the lamellar thickening index $\beta$ can also be calculated (i.e., $\beta$ $=0.5 \times$ slope $^{-1}$ ), which equals 1.2 . The value of $\beta$ near one guaranteed (based on the assumptions of the Hoffman-Weeks derivation) that the extrapolation was valid and gave a reliable $T_{m}^{0}$ value,

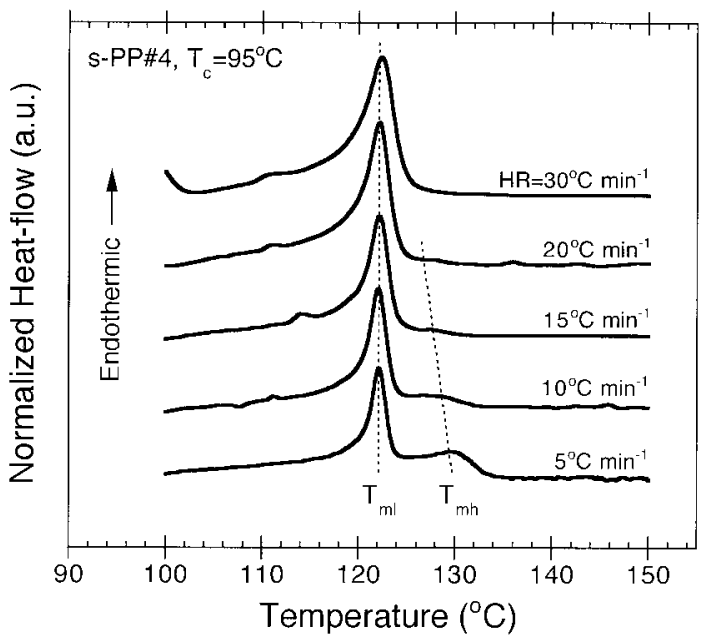

Figure 9 Melting endotherms of s-PP samples recorded using different heating rates ranging from 5 to $30^{\circ} \mathrm{C} \min ^{-1}$ after partial crystallization at $\left(T_{c}\right) 95^{\circ} \mathrm{C}$ for $15 \mathrm{~min}$. 
Table III Variation of Low-Melting Peak Temperature $\left(T_{\text {int }}\right)$, High-Melting Peak Temperature $\left(T_{\text {mh }}\right)$, and Enthalpy of Fusion $\left(\Delta H_{f}\right)$

\begin{tabular}{|c|c|c|c|c|c|c|}
\hline \multirow[b]{2}{*}{$\begin{array}{l}\text { Heat Rate } \\
\left({ }^{\circ} \mathrm{C} \min ^{-1}\right)\end{array}$} & \multicolumn{3}{|c|}{$T_{c}=75^{\circ} \mathrm{C}$ for $1.5 \mathrm{~min}$} & \multicolumn{3}{|c|}{$T_{c}=95^{\circ} \mathrm{C}$ for $15 \mathrm{~min}$} \\
\hline & $T_{\mathrm{ml}}\left({ }^{\circ} \mathrm{C}\right)$ & $T_{\mathrm{mh}}\left({ }^{\circ} \mathrm{C}\right)$ & $\begin{array}{c}\Delta H_{f} \\
\left(\mathrm{~J} \mathrm{~g}^{-1}\right)\end{array}$ & $T_{\mathrm{ml}}\left({ }^{\circ} \mathrm{C}\right)$ & $T_{\mathrm{mh}}\left({ }^{\circ} \mathrm{C}\right)$ & $\begin{array}{c}\Delta H_{f} \\
\left(\mathrm{~J} \mathrm{~g}^{-1}\right)\end{array}$ \\
\hline 5 & 113.9 & 126.8 & 30.6 & 123.1 & 130.0 & 8.7 \\
\hline 10 & 114.0 & 125.5 & 23.0 & 123.1 & 128.8 & 3.1 \\
\hline 15 & 114.0 & 124.6 & 14.6 & 123.2 & - & 2.2 \\
\hline 20 & 114.0 & 123.6 & 10.8 & 123.2 & - & 2.3 \\
\hline \multirow[t]{2}{*}{30} & 114.5 & 123.3 & 6.6 & 123.4 & - & 1.6 \\
\hline & $114.1 \pm 0.2$ & $127.7 \pm 1.4$ & & $123.2 \pm 0.1$ & $129.4 \pm 0.8$ & \\
\hline
\end{tabular}

The variations were determined from Figures 8 and 9 with the heating rate used to record the subsequent melting endotherms after partial crystallization at $\left(T_{c}\right) 75^{\circ} \mathrm{C}$ for $1.5 \mathrm{~min}$ and $95^{\circ} \mathrm{C}$ for $15 \mathrm{~min}$, respectively.

because the $T_{m}$ values observed for different $T_{c}$ values were not greatly affected by the lamellar thickening process, which was in a good agreement with our results discussed previously. It should be noted that the extrapolation on the $T_{\mathrm{mh}}$ was carried out just to provide a comparison to the results obtained on the $T_{\mathrm{ml}}$ data.

Even though the correlation coefficient $\left(r^{2}\right)$ of the linear Hoffman-Weeks fit was very close to one (i.e., $r^{2}=0.995$ ), a slightly upward curvature of the data was clearly discernable. This upward curvature in the observed $T_{\mathrm{m}}$ versus $T_{c}$ data was also observed in various polymer systems, ${ }^{79,80}$ thus raising a concern on the assumed constancy of the $\beta$. In fact, Weeks ${ }^{81}$ pointed out long ago that the increase in the observed $T_{\mathrm{m}}$ value with increasing crystallization time may be a result of the lamellar thickening, which has a logarithmic dependence on time. This simply means that the thickening effect is much more severe at higher $T_{c}$ values (as a result of a combination of high molecular mobility and a small relaxation time) where prolonged crystallization time is needed for complete crystallization.

Although the nonlinearity in the observed $T_{m}$ - $T_{c}$ data over a wide range of temperatures was explained to some extent by Alamo et al. ${ }^{79}$ it is the recent contribution by Marand et al. ${ }^{82}$ that offers a new method of determining the $T_{m}^{0}$ value based on the observed $T_{m}-T_{c}$ data: the observed $T_{m}$ data were taken from samples crystallized at different temperatures but with the same $a$ priori lamellar thickening coefficient. Based on the Gibbs-Thomson equation [see eq. (1)] and the proposition of Lauritzen and Passaglia ${ }^{83}$ on the stem length fluctuation during chain folding, Ma- rand et al. ${ }^{82}$ proposed a new mathematical derivation that states a relationship between the observed $T_{m}$ and the corresponding $T_{c}$. This equation is called the nonlinear Hoffman-Weeks extrapolation (NLHW), and is written in the form

$$
\frac{T_{m}^{0}}{T_{m}^{0}-T_{m}}=\beta^{m} \frac{\sigma_{e}^{1}}{\sigma_{e}^{G T}}\left[\frac{T_{m}^{0}}{T_{m}^{0}-T_{c}}+\frac{D_{2} \Delta H_{f}^{0}}{2 \sigma_{e}^{1}}\right]
$$

or in a simpler form,

$$
M=\beta^{m} \frac{\sigma_{e}^{1}}{\sigma_{e}^{\mathrm{GT}}}(X+a)
$$

where $\beta^{m}$ is the thickening coefficient [see $\beta$ in eq. $(2)], \sigma_{e}^{G T}$ is the fold surface free energy associated with a nucleus of critical size including the extra lateral surface energy due to fold protrusion and the mixing entropy associated with stems of different lengths $\left(\sigma_{e}^{G T} \equiv \sigma_{e}\right.$ in the Gibbs-Thomson equation), $\sigma_{e}^{1}$ is the interfacial energy associated with the basal plane of the mature crystallite, $D_{2}$ is a constant, and all other parameters are the same as previously defined. It is worth noting that for most cases it is safe to assume that $\sigma_{e}^{1}=$ $\sigma_{e}^{G T} .^{82}$ Precautionary remarks regarding the use of the nonlinear Hoffman-Weeks procedure to estimate the $T_{m}^{0}$ were addressed in detail in the original publication by Marand et al. ${ }^{82}$

In order to apply eq. (3) to analyze the experimental $T_{m}-T_{c}$ data in real polymer systems, it is required that the observed $T_{m}$ data be collected from samples crystallized at different tempera- 


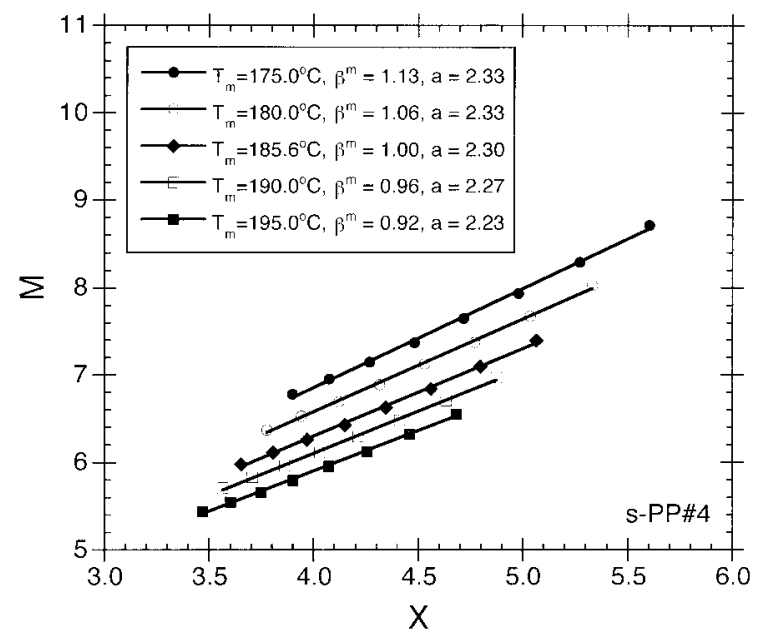

Figure 10 Plots of the scaled observed melting temperature $\left[M=T_{m}^{0} /\left(T_{m}^{0}-T_{m}\right)\right]$ versus the scaled crystallization temperature $\left[X=T_{m}^{0} /\left(T_{m}^{0}-T_{c}\right)\right]$ for various choices of the seeded equilibrium melting temperature $\left(T_{m}^{0}\right)$.

tures but having the same lamellar thickening coefficient $\beta^{m}$. For each set of the observed $T_{m}-$ $T_{c}$ data, corresponding values of $M$ and $X$ in eq. (3) can be calculated for a given choice of the $T_{m}^{0}$. For the case of $\sigma_{e}^{1}=\sigma_{e}^{G T}$, the actual $T_{m}^{0}$ is taken as the seed $T_{m}^{0}$ value, which results in the plot of $M$ versus $X$ being a straight line with a slope of unity (i.e., $\beta^{m}=1$ ) and intercept of $a$ (i.e., $a=D_{2} \Delta H_{f}^{0}$ / $\left.2 \sigma_{e}^{1}\right)$. Because it was shown previously that lamellar thickening did not occur in s-PP during crystallization, at least within the $T_{c}$ range studied,

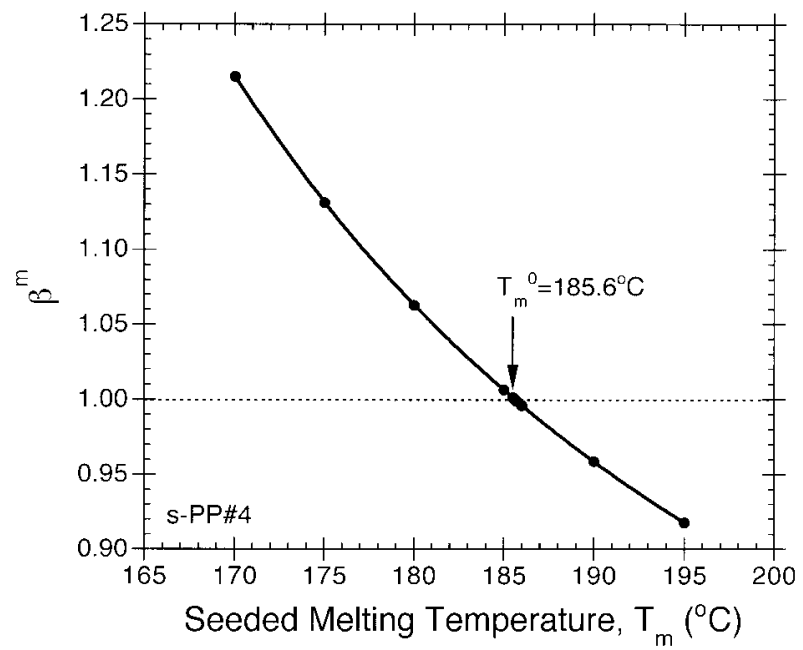

Figure 11 The variation of the thickening coefficient $\left(\beta^{m}\right)$ as a function of the seeded equilibrium melting temperature.

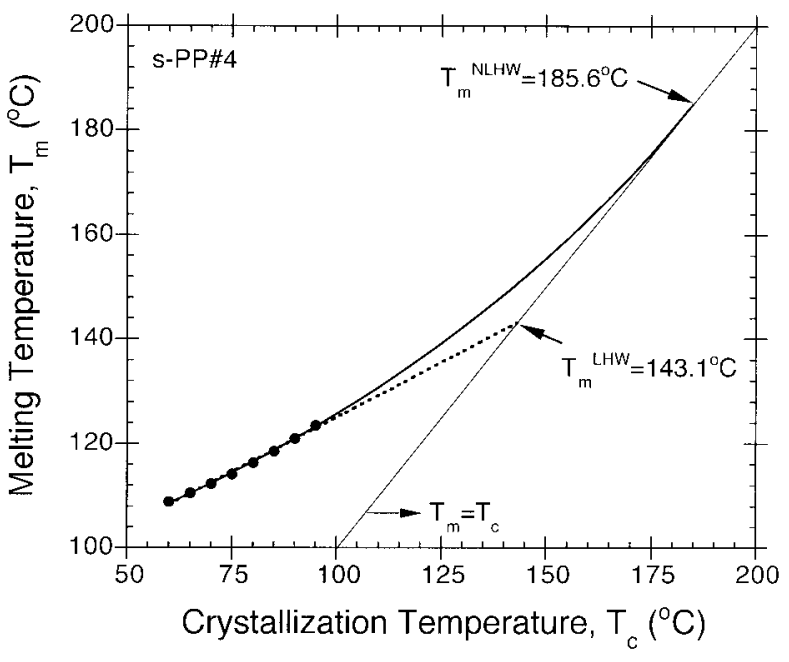

Figure 12 A plot of the observed melting temperature of the primary crystallites versus the crystallization temperature. (-) The nonlinear Hoffman-Weeks extrapolation calculated using $\beta^{m}=1.00$ and $a$ $=2.30 .(\cdots)$ The linear Hoffman-Weeks extrapolation (also shown in Fig. 3).

we can reasonably assume that the observed $T_{m}$ data summarized in Table I were collected from lamellae having the same $\beta^{m}$, thus making them eligible to be analyzed according to this method.

Figure 10 shows variation of the $M$ versus $X$, which was calculated from the data shown in Table I for different choices of the seeded $T_{m}^{0}$. Figure 11 shows the variation in the slope of the plots of $M$ versus $X$. Based on the virtue of this method, the equilibrium melting temperature $T_{m}^{0}$ for this s-PP resin was found to be $185.6^{\circ} \mathrm{C}$ (for $\beta^{m}$ $=1$ ). The value of $a$ associated with the resulting $T_{m}^{0}$ value was determined from the $y$ intercept of the plot of $M$ versus $X$ and was found to be 2.30. The linear and nonlinear Hoffman-Weeks extrapolations of the observed $T_{m}-T_{c}$ data are plotted in Figure 12. It should be noted that the $r^{2}$ of the fit obtained for both methods suggested that the nonlinear Hoffman-Weeks extrapolation gave a better fit to the bulk of the data than the linear Hoffman-Weeks extrapolation $\left(r^{2}=0.998\right.$ in NLHW vs. 0.995 in LHW).

\section{CONCLUSIONS}

Subsequent melting thermograms of s-PP after isothermal crystallization at various $T_{c}$ values exhibited either double- or triple-melting endo- 
therms, depending on the $T_{c}$ studied. For isothermal crystallization at a $T_{c}$ of $\leq 90^{\circ} \mathrm{C}$, triple-melting endotherms were observed whereas only double-melting endotherms were observed for a $T_{c}$ of $\geq 90^{\circ} \mathrm{C}$. For subsequent melting thermograms exhibiting triple-melting endotherms, the minor and the $T_{\mathrm{ml}}$ values corresponded to the melting of the secondary and the primary crystallites formed at corresponding $T_{c}$ values, respectively, while the $T_{\mathrm{mh}}$ represented the melting of the recrystallized crystallites formed during a subsequent heating scan. The formation of the recrystallized crystallites was found to be a result of the recrystallization of the crystallizable materials after the melting of the secondary crystallites and the partial melting of the less stable fractions of the primary crystallites formed at the $T_{c}$. The existence of the $T_{\mathrm{mh}}$ was found to strongly depend on the stability of the secondary and the primary crystallites formed and on the scanning rate used during the heating scan.

Based on the present analysis, the primary crystallites formed at the $T_{c}$ did not thicken during crystallization, at least within the $T_{c}$ range studied. The thickening process was thought to be a kinetically controlled mechanism in nature. The secondary crystallization was found to occur at a later stage of the crystallization process, most likely after the impingement of the macroscopic crystalline aggregates onto one another. The formation of the secondary crystallites was thought to occur from crystallization of either the interlamellar crystallizable amorphous materials or the interfibrillar amorphous materials (or both), depending on the crystallization conditions studied. Because of the fact that the minor endotherm was always found located close to the corresponding $T_{c}$, the thickness of the secondary lamellae had to be thinner than that of the primary lamellae formed at the same temperature.

The analysis of the observed $T_{m}$ of the primary crystallites and the corresponding $T_{c}$ according to the linear and nonlinear Hoffman-Weeks extrapolations gave $T_{m}^{0}$ values for this s-PP resin of 143.1 and $185.6^{\circ} \mathrm{C}$, respectively.

The author would like to thank Dr. Joseph Schardl of Fina Oil and Chemical Company (Dallas, TX) for supplying the s-PP resin used in this study and Dr. Roger A. Phillips and his colleagues of Montell USA, Inc. (Elkton, MD) for performing sample characterizations. In addition, a grant provided by Chulalongkorn University through the Development Grants for New Faculty/Researchers is gratefully acknowledged.

\section{REFERENCES}

1. Natta, G.; Pasquon, I.; Corradini, P.; Peraldo, M.; Pegoraro, M.; Zambelli, A. Rend Acad Naz Lincei 1960, 28, 539.

2. Natta, G.; Pasquon, I.; Zambelli, A. J Am Chem Soc 1962, 84, 1488.

3. Ewen, J. A.; Johns, R. L.; Razavi, A.; Ferrara, J. D. J Am Chem Soc 1988, 110, 6255.

4. Rodriguez-Arnold, J.; Bu, Z.; Cheng, S. Z. D. J Macromol Sci Rev Macromol Chem Phys 1995, C35, 117.

5. Schardl, J.; Sun, L.; Kimura, S.; Sugimoto, R. J Plast Film Sheeting 1996, 12, 157.

6. Sun, L.; Shamshoum, E.; DeKunder, G. SPE-ANTEC Proc 1996, 1965.

7. Gownder, M. SPE-ANTEC Proc 1998, 1511.

8. Sura, R. K.; Desai, P.; Abhiraman, A. S. SPE-ANTEC Proc 1999, 1764.

9. Supaphol, P.; Hwu, J. J.-J.; Phillips, P. J.; Spruiell, J. E. SPE-ANTEC Proc 1997, 1759.

10. Supaphol, P.; Spruiell, J. E. J Appl Polym Sci 2000, 75, 44.

11. Alamo, R. G.; Mandelkern, L. J Polym Sci Polym Phys 1986, 24, 2087.

12. Freedman, A. M.; Bassett, D. C.; Vaughan, A. S.; Olley, R. H. Polymer 1986, 27, 1163.

13. Samuels, R. J. J Polym Sci Polym Phys 1975, 13, 1417.

14. Alberola, N.; Fugier, M.; Petit, D.; Fillon, B. J Mater Sci 1995, 30, 1187.

15. Lovering, E. G.; Wooden, D. C. J Polym Sci A-2 1969, 7, 1639.

16. Yoo, E. S.; Im, S. S. J Polym Sci Polym Phys 1999, 37, 1357.

17. Liberti, F. N.; Wunderlich, B. J Polym Sci A-2 1968, $6,833$.

18. Bell, J. P.; Slade, P. E.; Dumbleton, J. H. J Polym Sci A-2 1968, 6, 1773.

19. Xenopoulos, A.; Wunderlich, B. J Polym Sci Polym Phys 1990, 28, 2271.

20. Lemstra, P. J.; Kooistra, T.; Challa, G. J Polym Sci A-2 1972, 10, 823.

21. Woo, E. M.; Wu, F. S. Macromol Chem Phys 1998, 199, 2041.

22. Holdsworth, P. J.; Turner-Jones, A. Polymer 1971, $12,195$.

23. Zhou, C.-X.; Clough, S. B. Polym Eng Sci 1988, 28, 65.

24. Woo, E. M.; Ko, T. Y. Colloid Polym Sci 1996, 274, 309.

25. Medellin-Rodriguez, F. J.; Phillips, P. J.; Lin, J.-S.; Campos, R. J Polym Sci Polym Phys 1997, 35, 1757.

26. Tan, S.; Su, A.; Li, W.; Zhou, E. Macromol Rapid Commun 1998, 19, 11.

27. Wang, Z.-G.; Hsiao, B. S.; Sauer, B. B.; Kampert, W. G. Polymer 1999, 40, 4615.

28. Stein, R. S.; Misra, A. J Polym Sci Polym Phys 1980, 18, 327. 
29. Blundell, D. J. Polymer 1987, 28, 2248.

30. Kim, H. G.; Robertson, R. E. J Polym Sci Polym Phys 1998, 36, 1757.

31. Hsiao, B. S.; Wang, Z.-G.; Yeh, F.; Gao, Y.; Sheth, K. C. Polymer 1999, 40, 3515.

32. Cheng, S. Z. D.; Wu, Z.-Q.; Wunderlich, B. Macromolecules 1987, 20, 2802.

33. Huo, P.; Cebe, P. Colloid Polym Sci 1992, 270, 840.

34. Blundell, D. J.; Osborn, B. N. Polymer 1983, 24, 953.

35. Cebe, P.; Hong, S.-D. Polymer 1986, 27, 1183.

36. Cheng, S. Z. D.; Cao, M. Y.; Wunderlich, B. Macromolecules 1986, 19, 1868.

37. Lee, Y.; Porter, R. S. Macromolecules 1987, 20, 1336.

38. Bassett, D. C.; Olley, R. H.; Raheil, I. A. M. Polymer 1988, 29, 1745.

39. Lee, Y.; Porter, R. S.; Lin, J.-S. Macromolecules 1989, 22, 1756.

40. Lattimer, M. P.; Hobbs, J. K.; Hill, M. J.; Barham, P. J. Polymer 1992, 33, 3971.

41. Wang, J.; Alvarez, M.; Zhang, W.; Wu, Z.; Li, Y.; Chu, B. Macromolecules 1992, 25, 6943.

42. Jonas, A.; Legras, R. Macromolecules 1993, 26, 813.

43. Kruger, K.-N.; Zachmann, H. G. Macromolecules 1993, 26, 5202.

44. Hsiao, B. S.; Gardner, K. H.; Wu, D. Q.; Chu, B. Polymer 1993, 34, 3986.

45. Hsiao, B. S.; Gardner, K. H.; Wu, D. Q.; Chu, B. Polymer 1993, 34, 3996.

46. Jonas, A.; Russell, T. P.; Yoon, D. Macromolecules 1995, 28, 8491.

47. Verma, R. K.; Velikov, V.; Kander, R. G.; Marand, H.; Chu, B.; Hsiao, B. S. Polymer 1996, 37, 5357.

48. Verma, R. K.; Marand, H.; Hsiao, B. S. Macromolecules 1996, 29, 7767.

49. Verma, R. K.; Hsiao, B. S. TRIP 1996, 4, 312.

50. Ji, X.-L.; Zhang, W.-J.; Wu, Z.-W. J Polym Sci Polym Phys 1997, 35, 431.

51. Supaphol, P.; Spruiell, J. E. J Appl Polym Sci 2000, $75,337$.

52. Rodriguez-Arnold, J.; Zhang, A.; Cheng, S. Z. D.; Lovinger, A. J.; Hsieh, E. T.; Chu, P.; Johnson, T. W.; Honnell, K. G.; Geerts, R. G.; Palackal, S. J.; Hawley, G. R.; Welch, M. B. Polymer 1994, 35, 1884.

53. Schmidtke, J.; Strobl, G.; Thurn-Albrecht, T. Macromolecules 1997, 30, 5804.

54. Hauser, G.; Schmidtke, J.; Strobl, G. Macromolecules $1998,31,6250$

55. Corradini, P.; Natta, G.; Ganis, P.; Temussi, P. A. J Polym Sci C 1967, 16, 2477.

56. Lotz, B.; Lovinger, A. J.; Cais, R. E. Macromolecules 1988, 21, 2375.

57. Lovinger, A. J.; Lotz, B.; Davis, D. D. Polymer 1990, 31, 2253.
58. Lovinger, A. J.; Davis, D. D.; Lotz, B. Macromolecules 1991, 24, 552.

59. Lovinger, A. J.; Lotz, B.; Davis, D. D.; Padden, F. J. Macromolecules 1993, 26, 3494.

60. Chatani, Y.; Maruyama, H.; Noguchi, K.; Asanuma, T.; Shiomura, T. J Polym Sci C 1990, 28, 393.

61. Chatani, Y.; Maruyama, H.; Asanuma, T.; Shiomura, T. J Polym Sci Polym Phys 1991, 29, 1649.

62. De Rosa, C.; Corradini, P. Macromolecules 1993, 26, 5711 .

63. Auriemma, F.; De Rosa, C.; Corradini, P. Macromolecules 1993, 26, 5719.

64. De Rosa, C.; Auriemma, F.; Corradini, P. Macromolecules 1996, 29, 7452.

65. Lovinger, A. J.; Lotz, B. J Polym Sci Polym Phys 1997, 35, 2523.

66. De Rosa, C.; Auriemma, F.; Vinti, V. Macromolecules 1997, 30, 4137.

67. Auriemma, F.; De Rosa, C.; Ruiz de Ballesteros, O.; Vinti, V.; Corradini, P. J Polym Sci Polym Phys 1998, 36, 395.

68. De Rosa, C.; Auriemma, F.; Vinti, V.; Grassi, A.; Galimberti, M. Polymer 1998, 39, 6219.

69. De Rosa, C.; Auriemma, F.; Vinti, V. Macromolecules 1998, 31, 7430.

70. De Rosa, C.; Talarico, G.; Caporaso, L.; Auriemma, F.; Galimberti, M.; Fusco, O. Macromolecules 1998, 31, 9109

71. Brown, R. G.; Eby, R. K. J Appl Phys 1964, 35, 1156.

72. Hoffman, J. D.; Davis, G. T.; Lauritzen, J. I., Jr. In Treatise on Solid State Chemistry; Hannay, N. B., Ed.; Plenum: New York, 1976; Vol. 3, Chap. 7.

73. Hugel, T.; Strobl, G.; Thomann, R. Acta Polym 1999, 50, 214.

74. Marand, H.; Alizadeh, A. ACS-PMSE Prepr 1999, 81, 238.

75. Vancso, G. J.; Beekmans, L. G. M.; Trifonova, D.; Varga, J. ACS-PMSE Prepr 1999, 81, 232.

76. Taguchi, K.; Miyaji, H.; Izumi, K.; Hoshino, A.; Miyamoto, Y.; Kokawa, R. ACS-PMSE Prepr 1999, 81, 308.

77. Carfagna, C.; De Rosa, C.; Guerra, G.; Petraccone, V. Polymer 1984, 25, 1462.

78. Hoffman, J. D.; Weeks, J. J. J Res Natl Bur Stand 1962, A66, 13.

79. Alamo, R. G.; Viers, B. D.; Mandelkern, L. Macromolecules 1995, 28, 3205.

80. Huang, J.; Prasad, A.; Marand, H. Polymer 1994, 35, 1896.

81. Weeks, J. J. J Res Natl Bur Stand 1963, A67, 441.

82. Marand, H.; Xu, J.; Srinivas, S. Macromolecules 1998, 31, 8219

83. Lauritzen, J. I., Jr.; Passaglia, E. J Res Natl Bur Stand 1967, A71, 261. 